\title{
Prognostic Significance of Exercise-Induced Left Ventricular Dysfunction in Chronic Aortic Regurgitation
}

\author{
DAVID S. GEE, MD, JACK E. JUNI, MD, JOHN T. SANTINGA, MD, \\ and ANDREW J. BUDA, MD
}

Twenty-three patients with hemodynamically significant aortic regurgitation (AR) underwent gated equilibrium radionuclide angiography to assess rest and exercise left ventricular ejection fraction (LVEF) before and after aortic valve replacement. Preoperatively, LVEF decreased from $54 \pm 3 \%$ at rest to $45 \pm 3 \%$ during exercise $(p<0.001)$. Two patients died at operation. Postoperatively, after 5.7 \pm 1.6 months, LVEF was $62 \pm 5 \%$ at rest and $60 \pm$ $4 \%$ during exercise (difference not significant). Exercise LVEF improved significantly postopera- tively $(p<0.01)$. The patients were followed for a mean of 30 months (range 1 to 56 ), after valve replacement and during this period, 13 patients were in functional class I, 5 patients were in class II and 2 patients were in class III. One late death occurred and was unrelated to myocardial failure. Thus, in most patients with AR, exercise LVEF improves after aortic valve replacement. A preoperative decrease in LVEF during exercise in patients with significant AR does not predict a poor postoperative outcome.
(Am J Cardiol 1985;56:605-609)
The timing of valve replacement in chronic aortic regurgitation (AR) is controversial. Several hypotheses have been proposed concerning the development of irreversible myocardial dysfunction in chronic AR and the identification of patients at high risk for surgical intervention. ${ }^{1-11}$ Among these is the suggestion that a preoperative decrease in radionuclide left ventricular (LV) ejection fraction (EF) may predict a high-risk group of patients who may have subsequent deterioration in myocardial function after aortic valve replacement. $^{5-7}$ We evaluated the rest and exercise LVEF in patients with chronic AR before and after aortic valve replacement and assessed the prognostic significance of a preoperative exercise-induced decrease in LVEF.

\section{Methods}

Sixty-two patients were identified who had undergone aortic valve replacement between 1978 and 1982. Twentythree of these patients met the criteria for inclusion in our study: (1) chronic AR with no other significant valvular disease, (2) preoperative rest and exercise radionuclide angiography performed within 4 months of valvular replacement, (3) cold potassium cardioplegia for myocardial preservation during valve replacement, and (4) no history of endocarditis or intravenous drug abuse.

Equilibrium gated radionuclide angiography was performed with in vivo labeling of red blood cells. ${ }^{12,13}$ Patients performed symptom-limited, graded, supine exercise on a bicycle ergometer. Rest and peak exercise LVEF were calculated using

From the Cardiology and Nuclear Medicine Divisions, Department of Internal Medicine, University of Michigan Medical Center, Ann Arbor, Michigan. Manuscript received February 28, 1985; revised manuscript received April 18, 1985, accepted April 23, 1985.

Address for reprints: Andrew J. Buda, MD, Cardiology Division, University of Michigan Hospitals, 1405 East Ann Street, Ann Arbor, Michigan 48109. a commercial semiautomated, edge-detection algorithm to determine background-corrected $\mathrm{LV}$ counts on a frame-byframe basis. All preoperative radionuclide studies were done within 4 months of surgery and all postoperative studies were done no earlier than 6 months after valve replacement. Wall motion was assessed by consensus of 2 observers at rest and during peak exercise.

All patients underwent right- and left-sided cardiac catheterization preoperatively. In addition to supravalvular and biplane LV angiography, coronary arteriography was performed in all patients older than 40 years. AR was graded on a $4+$ scale using standard criteria. ${ }^{14}$

All patients were interviewed concerning their current New York Heart Association functional status. The patient's functional status and medications being used were reviewed at that time. In addition, follow-up on any cardiac-related complications was determined.

Results are reported as mean \pm standard error of the mean. Standard statistical techniques, including Pearson's correlation coefficient and $t$ tests, were used.

\section{Results}

The results are tabulated in Table I. The study group included 15 men and 8 women, mean age 55 years (range 26 to 72 ). The mean known duration of AR was 29 months (range 0 to 144). The cause of AR was rheumatic heart disease in 13 patients, and bicuspid aortic valve with a perforated right cusp in 1 patient; the cause was unknown in 9 patients. Four patients had previous hospital admissions for congestive heart failure. The predominant symptoms were shortness of breath with exertion in 14 patients, chest pain in 7 patients, and syncope in 3 patients.

Preoperative cardiac catheterization data: All patients had at least grade $3 / 4 \mathrm{AR}$ by aortic root cineangiography, with a mean severity score of 3.8 . The mean cardiac output was $5.8 \pm 1.6$ liters $/ \mathrm{min}$ and $L V$ 


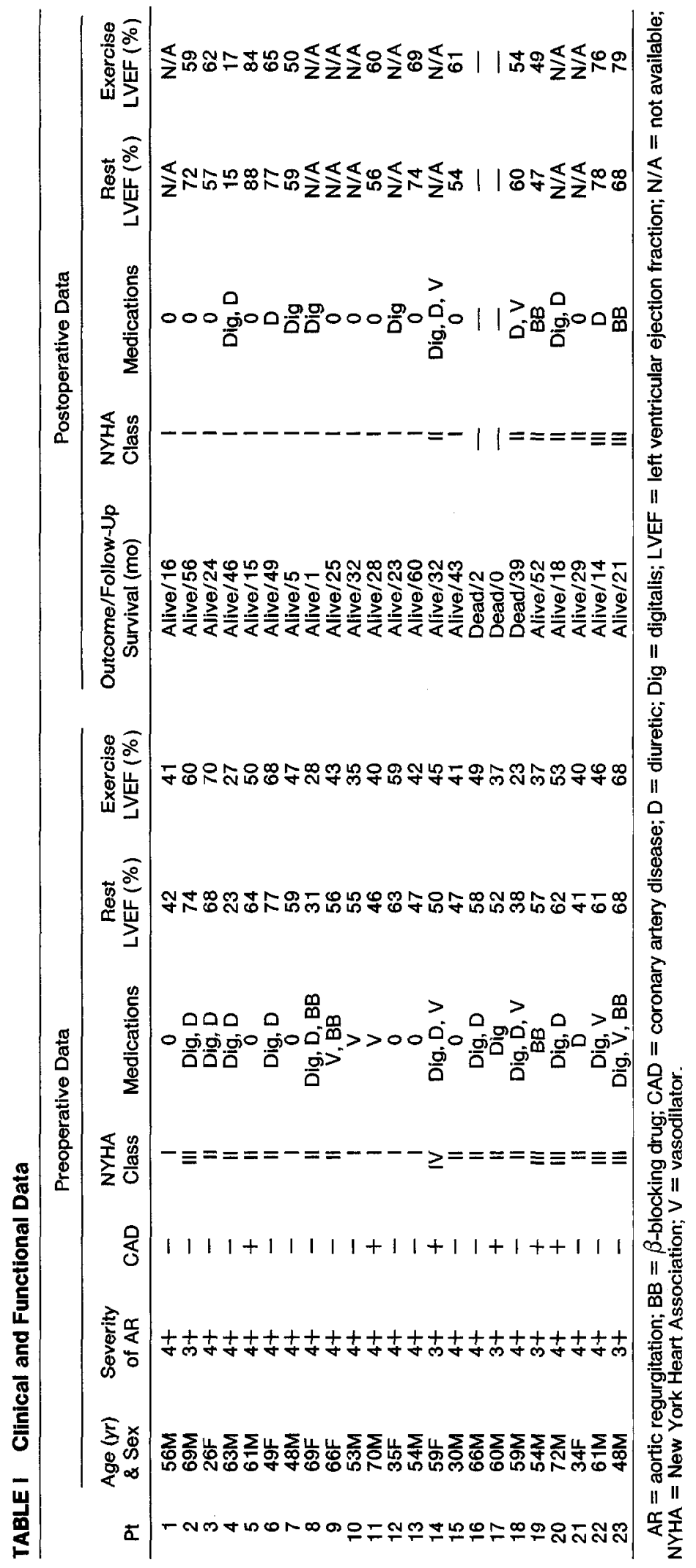


end-diastolic pressure was $16 \pm 2 \mathrm{~mm} \mathrm{Hg}$. Six patients had $70 \%$ or greater luminal stenosis of 1 or more major coronary arteries. Two patients each had 1-, 2- and 3vessel disease.

Preoperative radionuclide angiographic data: Preoperatively, LVEF at rest was $54 \pm 3 \%$, and it decreased significantly with exercise to $45 \pm 3 \%(\mathrm{p}<0.001)$ (Fig. 1). Only 2 patients, both in New York Heart Association functional class II, had an increase in LVEF, of $2 \%$ and $4 \%$, respectively, with exercise. Analysis of LV wall motion showed that wall motion worsened with exercise in 12 patients, did not change in 10 patients and improved in 1 patient.

Surgical results: There was only 1 perioperative cardiac-related death: a 60-year-old man (patient 17) with 3-vessel coronary disease died of intractable ventricular tachyarrhythmias after an intraoperative myocardial infarct. Another patient, a 66-year-old man (patient 16), died of respiratory failure caused by bilateral phrenic nerve paralysis. Twenty-one patients had no significant perioperative complications.

Seven patients received Björk-Shiley prosthetic valves, 5 received Starr-Edwards valves and 11 received porcine valves. All patients with mechanical valves received anticoagulation therapy before discharge from the hospital. Of the 6 patients with coronary artery disease, 4 underwent concurrent coronary artery bypass operation.

Postoperative radionuclide angiographic data: In 13 of the 23 patients, postoperative rest and exercise radionuclide angiographic studies were performed. The

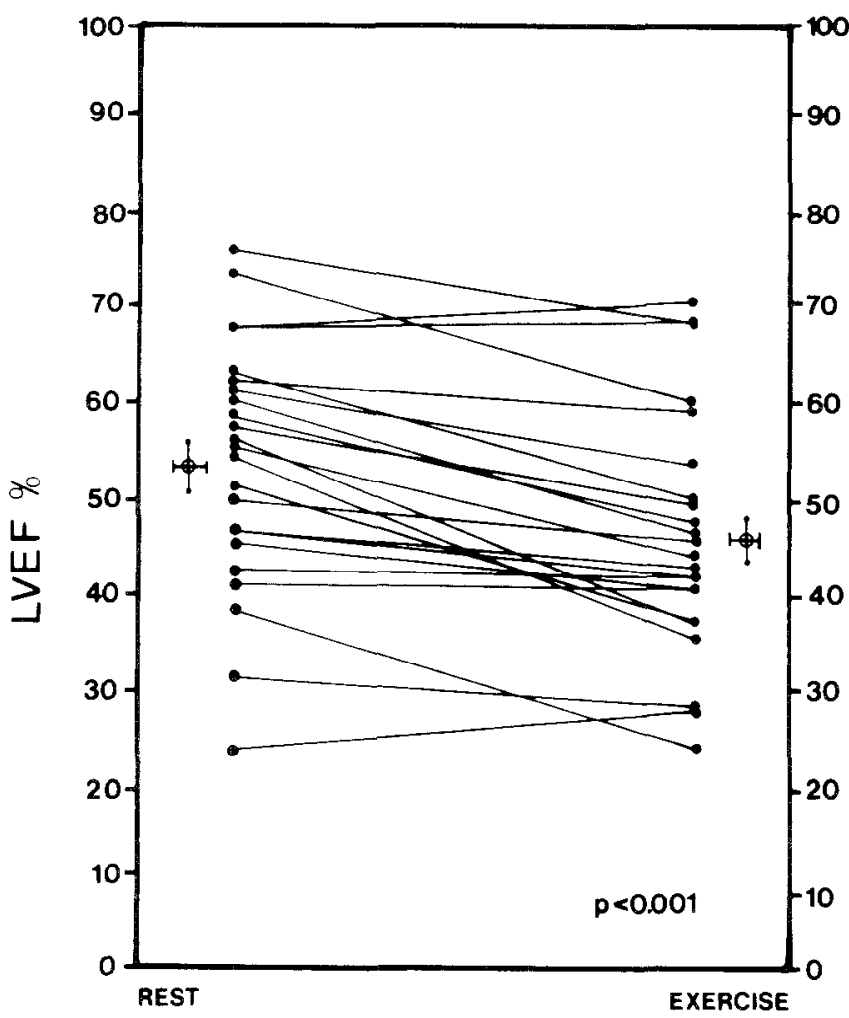

FIGURE 1. Preoperative change in left ventricular ejection fraction (LVEF) with exercise. studies were performed no earlier than 6 months after aortic valve replacement and at a mean of 9.2 months. Compared with preoperative values, there was no postoperative change in maximal rate-pressure product achieved $\left(217 \pm 10\right.$ vs $202 \pm 14 \mathrm{~mm} \mathrm{Hg} / \mathrm{min} \times 10^{2}$, difference not significant [NS]). The postopcrative LVEF at rest in these 13 patients was $59 \pm 2 \%$; it increased to $60 \pm 4 \%$ during exercise (NS) (Fig. 2). Pre- and postoperative LVEF at rest in these 13 patients was not significantly different, $56 \pm 4 \%$ vs $62 \pm 5 \%(\mathrm{p}=0.19)$. However, there was a significant increase postoperatively in exercise LVEF, from $48 \pm 4 \%$ to $60 \pm 4 \%$ (p $<0.01$ ) (Fig. 3). A comparison of pre- and postoperative wall motion abnormalities showed that there was improvement in 7 patients, no change in 3 patients, worsening in 1 patient, and inadequate technique precluded comparison in 2 patients. Exclusion of patients with significant coronary artery disease or coronary artery bypass grafts did not influence any of the postoperative results.

Clinical follow-up: The mean patient follow-up period of the 21 surviving patients was 30 months (range 1 to 56). The change in New York Heart Association functional class is shown in Figure 4.

There was only 1 late death, a 59-year-old man (patient 18) with Marfan syndrome who died after aortic root replaccment 6 months after aortic valve replacement. Two patients with mechanical valves had cerebrovascular accidents despite therapeutic anticoagulation.

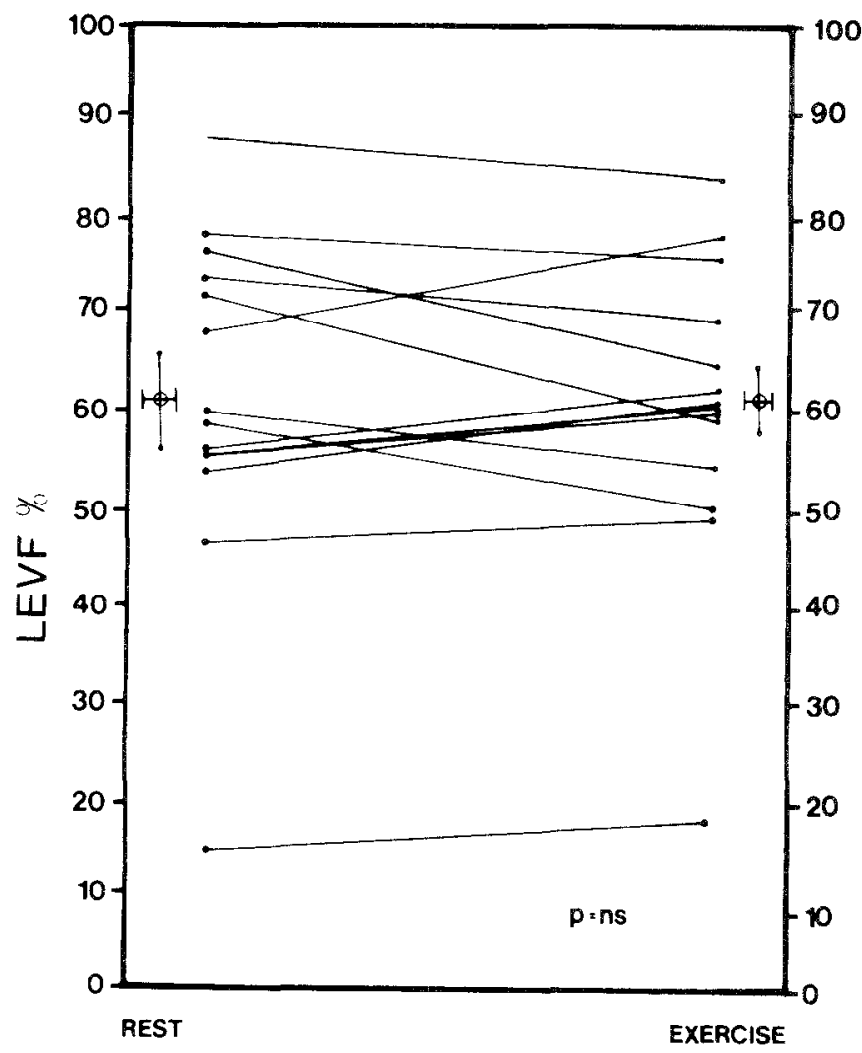

FIGURE 2. Postoperative change in left ventricular ejection fraction (LVEF) with exercise. NS = not significant. 


\section{Discussion}

A major concern in chronic AR has been the development of irreversible myocardial dysfunction, which results in late death from congestive heart failure despite technically successful valve replacement. For example, $78 \%$ of late postoperative deaths from 1972 to 1978 at the National Institutes of Health $(\mathrm{NIH})^{9}$ were related to chronic congestive heart failure. As a result, several prognostic indicators related to LV dimensions and systolic function have been proposed to aid in the appropriate timing of surgery and in the identification of the high-risk patient who may respond poorly to valve replacement and have late congestive heart failure. ${ }^{1-11}$

In our study, all asymptomatic patients had a decrease in LVEF with exercise. Previous studies ${ }^{5-7}$ have shown that most asymptomatic and symptomatic patients with chronic AR have an abnormal ejection fraction response during maximal supine exercise. It has been hypothesized that the decrease in radionuclide LVEF with exercise may represent an intermediate point between normal function and $\mathrm{LV}$ dysfunction at rest. ${ }^{5}$ It has been further suggested that an abnormal exercise ejection fraction response may allow selection of patients for operation after ventricular function has begun to deteriorate, but before myocardial damage has progressed to the point at which postoperative prognosis is poor. ${ }^{6}$ However, exercise is a complex intervention that induces changes in preload, afterload and contractility, which may affect ejection fraction variably

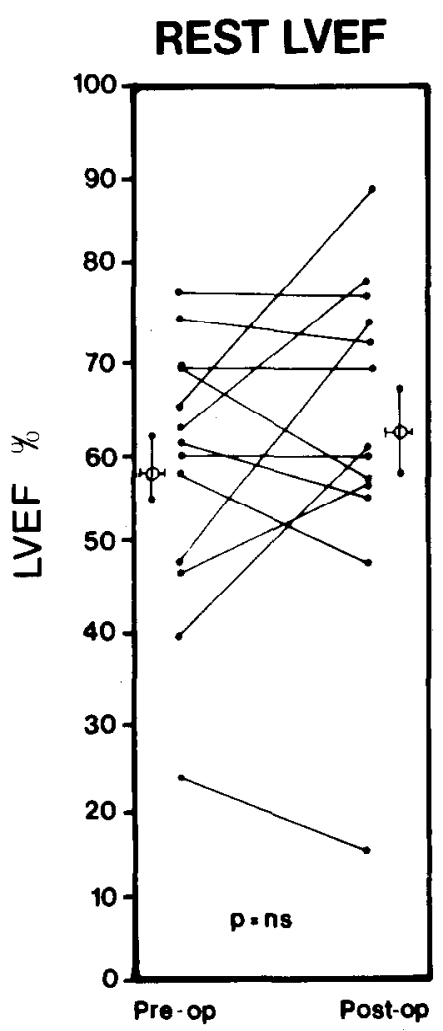

\section{EXERCISE LVEF}

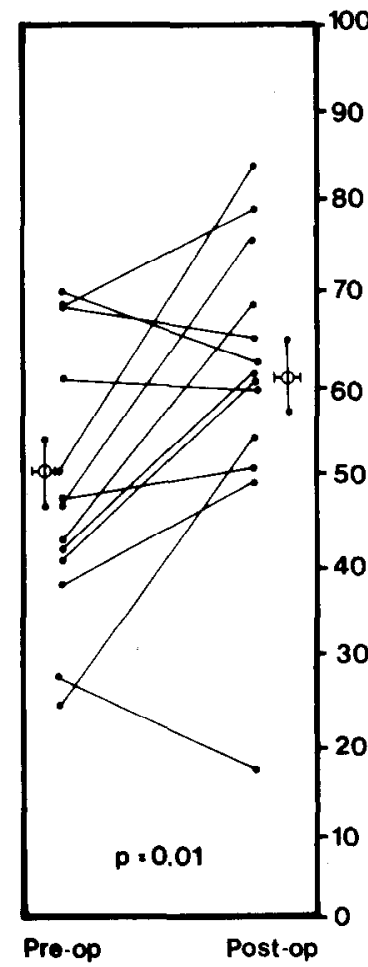

FIGURE 3. Comparison of preoperative and postoperative rest and exercise left ventricular ejection fraction (LVEF). in chronic AR. ${ }^{15}$ Thus, it is difficult or impossible to differentiate a change in $\mathrm{EF}$ in chronic $\mathrm{AR}$ because of marked loading perturbations from that resulting from myocardial degenerative changes.

The primary finding in our study was that despite a decrease in preoperative exercise LVEF, patients with chronic AR had an excellent postoperative course. After a mean follow-up of 30 months, no patient who survived surgery had died or had congestive heart failure. These data suggest that exercise-induced $L V$ dysfunction is compatible with a good long-term postoperative result and does not necessarily predict a poor postoperative course.

There is increasing evidence that exercise-induced LV dysfunction in symptomatic patients is often reversible after surgery. ${ }^{7,16,17}$ In a consecutive series from 1976 to $1980,93 \%$ of patients who underwent surgery at the NIH had an improvement in postoperative exercise LVEF. ${ }^{7}$ In our series, there was a postoperative improvement in $64 \%$ of our patients. Unlike the NIH series, we did not find a significant improvement in the rest LVEF, probably because our patients had generally better LV function at rest than those of the NIH series. However, the long-term prognosis of patients who have an abnormal exercise LVEF before surgery has not been previously reported.

Our survival results after aortic valve replacement appear better than those previously reported. ${ }^{7,18-20}$ This apparent improvement in survival has several possible explanations. First, all of our patients had cold potassium cardioplegia at the time of aortic valve replacement, which may have limited perioperative myocardial damage. Many data support the concept that advances in myocardial preservation techniques during surgery have improved postoperative survival. ${ }^{3,21,22}$ Second,

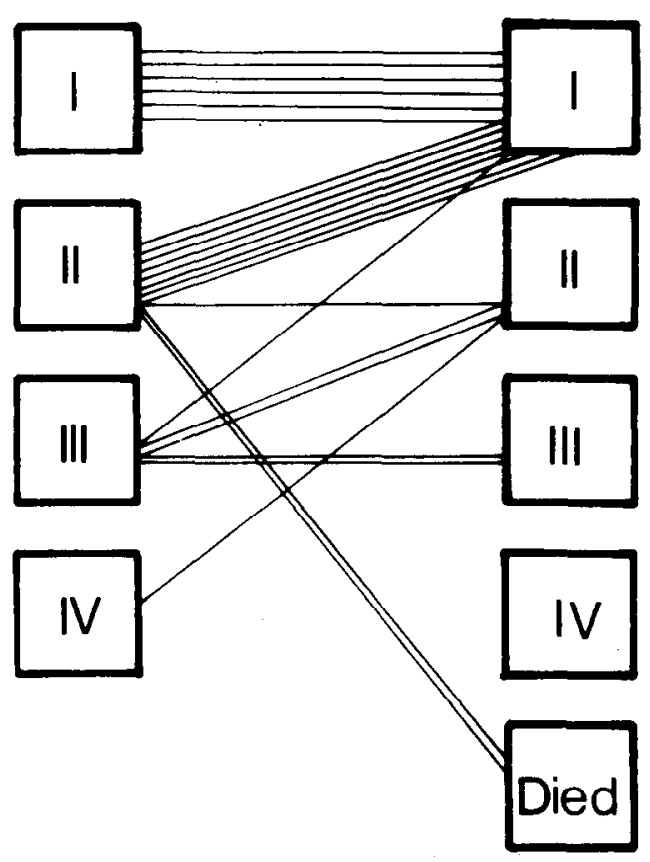

FIGURE 4. Changes in New York Heart Association functional class after valve replacement. 
most of our patients with coronary artery disease underwent coronary bypass grafting. Myocardial revascularization may have improved long-term survival, although the benefits of coronary bypass grafting in patients with chronic AR remains controversial. ${ }^{23}$ Third, exercise radionuclide abnormalities may have influenced the selection of patients for earlier operation; 6 of 23 patients werc asymptomatic and 11 were only mildly symptomatic. Recent data from the $\mathrm{NIH}^{17}$ suggest that there is a relation between the duration that $L V$ dysfunction has existed and the likelihood that this dysfunction is reversible. Patients with earlier development of $L V$ dysfunction are more likely to demonstrate normalization of $\mathrm{LV}$ function postoperatively than are patients whose LV dysfunction has been present longer than 1 year. None of our patients had serial radionuclide studies; thus, this relation may have influenced our survival results.

The precise role of the exercise EF response in patients with chronic AR remains to be determined. There are limited data on serial studies of rest and exercise LVEF in asymptomatic or symptomatic patients with chronic AR. Thus, the prognostic significance of a change in serial rest and exercise LVEF is uncertain. However, our data suggest that an exercised-induced abnormality in LVEF is common in patients being considered for aortic valve replacement and does not in itself predict a poor surgical result.

Acknowledgment: We gratefully acknowledge Sharon Haglund for her secretarial assistance.

\section{References}

1. Henry WL, Bonow RO, Borer JS, Ware JH, Kent KM, Redwood DR, MCIntosh CL, Morrow AG, Epstein SE. Observation on the optimum time for operative intervention for aortic regurgitation. I. Evaluation of the results of aortic valve replacement in symptomatic patients. Circulation 1980; 61:471-483.

2. Henry WL, Bonow RO, Rosing DR, Epstein SE. Observations on the optimum time for operative intervention for aortic regurgitation. II. Serial echocardiographic evaluation of asymptomatic patients. Circulation 1980;61:484-492.

3. Floretti P, Roelandt J, Bos RJ, Meltzer RS, Van Hoogenhuije D, Serruys PW, Nanta J, Hugenholtz PG. Echocardiography in chronic aortic insufficiency. Is valve replacement too late when left ventricular end-systolic dimension reaches $55 \mathrm{~mm}$ ? Circulation 1983;67:216-221.

4. Gaasch WH, Carroll JD, Levine JH, Criscitiello MG. Chronic aortic regur- gitation: prognostic value of left ventricular end-systolic dimensions and end-dlastollc radius/thickness ratio. JACC 1983;1:7775-782.

5. Borer JS, Bacharach SL, Green MV, Kent KM, Henry WL, Rosing DR, Seides SF, Johnson GS, Epstein SE. Exercise-induced left ventricular dysfunction in symptomatic and asymptomatic patients with aortic regurgitation. Am J Cardiol 1978;42:351-357.

6. Borer JS, Rosing DR, Kent KM, Bacharach SL, Green MV, Mclntosh CJ, Morrow AG, Epstein SE. Left ventricular function at rest and during exercise atter aortic valve replacement in patients with aortic regurgitation. Am J Cardial 1979;44:1297-1305.

7. Bonow RO, Rosing DR, Kent JM, Epstein SE. Timing of operation for chronic aortic regurgitation. Am J Cardiol 1982;50:325-336.

8. Bonow RO, Borer JS, Rosing DR, Henry WL, Pearlman AS, Mclntosh CL, Morrow AG, Epstein SE. Preoperative exercise capacity in symptomatic patients with aortic regurgitation as a predictor of postoperative left ventricular function and long-term prognosis. Circulation 1980;62:12801290.

9. Borow KM, Green LH, Mann T, Sloss LJ, Braunwald E, Collins JJ Jr, Cohn $L$, Grossman W. End-systolic volume as a predictor of postoperative left ventricular performance in volume overload from valvular regurgitation. Am J Med 1980;69:655-663.

10. Osbakken M, Bore AA, Spann JF. Left ventricular function in chronic aortic regurgitation with reference to end-systolic pressure, volume and stress relations. Am J Cardiol 1981;47:193-198.

11. Welss RJ, Buda AJ, LeMire MS, Pitt B. Assessment of dysfunction in aortic regurgitation by stress-shortening relationship. Int $\mathrm{J}$ Cardiol, in press

12. Thrall JH, Freitas JE, Swanson DP, Rogers WL, Clare JM, Brown ML, Pit B. Clinical comparison of cardiac blood pool visualization with technetium-99m red blood cells labelled in-vivo and with technetium-99m human serum albumin. J Nucl Med 1978;19:796-803.

13. Green MV, Brody WR, Douglas MA, Borer JS, Ostrow HG, Line BR, Bacharach SR, Johnson GS. Ejection fraction by count rate from gated images. J Nucl Med 1978;19:880-883.

14. Delaney D. Aortography. In: Grossman $W$, ed. Cardiac Catheterization and Angiography. Philadelphia, Lea \& Febiger, 1980:205.

15. Boucher CA, Wilson RA, Kanarek DJ, Hutter AM, Okada RD, Liberthson RR, Strauss HW, Pohost GM. Exercise testing in asymptomatic or minimally symptomatic aortic regurgitation: relationship of left ventricular ejection fraction to left ventricular filling pressure during exercise. Circulation 1983;67:1091-1100.

16. Bonow RO, Rosing DR, Mcintosh $\mathrm{CL}$, Jones $\mathrm{M}$, Maron BJ, Lan KKG, Lakalos E, Bacharach SL, Green MV, Epstein SE. The natural history of asymptomatic patients with aortic regurgitation and normal left ventricular function. Circulation 1983:68:509-517.

17. Bonow RO, Rosing DR, Maron BJ, Mclntosh $C_{L}$, Jones M, Bacharach SL, Green MV, Clark RE, Epstein SE. Reversal of left ventricular dysfunction after aortic valve replacement for chronic aortic regurgitation: influence of duration of preoperative left ventricular dysfunction. Circulation 1984; 70:570-579.

18. Barnhorst DA, Oxman HA, Connolly DC, Pluth JR, Danielson GK, Wallace RB, McGoon DC. Long-term follow-up of isolated replacement of the aortic or mitral valve with the Starr-Edwards prosthesis. Am J Cardiol 1975;35: 228-233.

19. Roberts DL, DeWeese JA, Mahoney EB, Yu PN. Long-term survival following aortic valve replacement. Am Heart, J 1976:91:311-317.

20. Rubin JW, Moore HV, Hillson RF, Ellison EG. Thirteen year experience with aortic valve replacement. Am J Cardiol 1977; 40:345-354

21. Kirklin JW, Conti VR, Blackstone EH. Prevention of myocardial damage during cardiac operations. N Engl J Med 1979;301:135 141.

22. Santinga JT, Kirsh MM, Brady TJ, Thrall J, Pitt B. Radionuclide angiography in evaluation of left ventricular function following aortic valve replacement. Ann Thor Surg 1981;31:409-413.

23. Bonow RO, Kent KM, Rosing DR, Lipson LC, Borer JS, Mclntosh CL, Morrow AG, Epstein SE. Aortic valve replacement without myocardial revascularization in patients with combined aortic vavlular and coronary artery disease. Circulation 1981;63:243 251 . 